\title{
MONITORAMENTO E AVALIAÇÃO EM PROJETOS DE RECUPERAÇÃO DE ÁREAS DEGRADADAS
}

\section{MONITORING AND ASSESSMENT OF RECUPERATION OF DEGRADED AREAS PROJECTS}

\author{
Gilberto Fugimoto de Andrade \\ Programa de Engenharia Ambiental - PEA/UFRJ \\ E-mail: gfugimoto@poli.ufrj.br \\ Gabriela Fernandez Sanchez \\ Faculdade de Ciências Econômicas/UERJ \\ E-mail: gbszfz@uerj.br \\ Josimar Ribeiro de Almeida \\ Observatório Urbano/UERJ/UN-Habitat \\ E-mail: almeida@poli.ufrj.br
}

\begin{abstract}
RESUMO
Atualmente, o ordenamento jurídico brasileiro determina a realização de Projetos de Recuperação de Áreas Degradadas (PRADs) como exigência nos processos de compensação ou licenciamento ambiental de atividades econômicas degradantes do meio ambiente. $O$ presente trabalho pretende abordar as etapas de Monitoramento e Avaliação, recursos gerenciais e estratégicos fundamentais para atestar o sucesso dos PRADs. Para tanto, são analisadas duas propostas de Monitoramento e Avaliação: (a) A Proposta SER (2004) que apresenta diretrizes universais de recuperação, 9 atributos de áreas restauradas e 3 estratégias de avaliação, embora não apresente indicadores RAD; e (b) A Proposta de Melo et al. (2010) que apresenta uma Matriz de Avaliação de Projetos de Restauração, com 7 indicadores RAD, organizados em 3 diferentes etapas da recomposição vegetal. Finalmente, sugere-se a incorporação das etapas de Monitoramento e Avaliação no planejamento de PRADs, como forma de contribuir para o aumento do conhecimento acerca dos processos de restauração.
\end{abstract}

Palavras-chave: Recuperação de Áreas Degradadas; Monitoramento; Avaliação; Restauração Ecológica.

\begin{abstract}
Currently, the Brazilian legal system determines the performance of Recuperation of degraded areas Projects (RDAPs) as a requirement in environmental compensation or licensing processes of economic activities degrading the environment. This study discusses the steps of Monitoring and Assessment, considered as key management and strategic resources to attest the success of RDAPs. To that end, we analyze two proposals for Monitoring and Assessment: (a) The SER (2004) proposed universal recovery guidelines, 9 attributes of restored areas and 3 assessment strategies, although it does not present ecological indicators; and (b) Melo et al. (2010) propose a Restoration Project Assessment Matrix, with 7 ecological indicators, organized in 3 different stages of plant recovery. Finally, we suggest the incorporation of the stages of monitoring and Assessment in the planning RDAPs as a way to increase knowledge about restoration processes.
\end{abstract}

Key words: Recuperation of Degraded Areas Projects; Monitoring; Assessment; Ecological Restoration. 


\section{A RECUPERAÇÃO DE ÁREAS DEgRADADAS: DESAFIOS E PERSPECTIVAS}

Nos últimos cinqüenta anos, a ação antrópica transformou os ecossistemas mais rápida e extensamente do que em qualquer outro período da humanidade, especialmente para atender a demanda crescente por comida, água, fibras e combustíveis. Neste sentido, a degradação de terras é a expressão mais ameaçadora da mudança dos ecossistemas, com impacto direto sobre o bem estar humano e social, especialmente na vida das populações mais pobres (ADEEL et al., 2005; VOGT et al., 2011).

Segundo o Relatório GLADA (Global Assessment of Land Degradation and Improvement), desenvolvido pelo ISRIC (International Soil Reference and Information Centre) para a FAO (Organização das Nações Unidas para Alimentação e Agricultura), com base no mapeamento de mudanças significativas na cobertura vegetal da superfície do planeta a partir de sensoriamento remoto, a magnitude do problema atinge $23,54 \%$ das terras disponíveis, abrangendo 35 milhões de quilômetros quadrados, afetando $23,89 \%$ da população mundial. No Brasil, o problema atinge 1,8 milhões de quilômetros quadrados, representando $22,11 \%$ do território nacional e 5,38\% das terras degradadas do planeta, afetando 4,7 milhões de habitantes ou $26,67 \%$ da população brasileira (BAl et al., 2008). Os dados estatísticos acerca da gravidade da degradação dos ecossistemas, durante os últimos vinte anos do século XX, em território brasileiro e mundial, apresentam-se recopilados na Tabela 1 a seguir.

Tabela 1. Degradação de Terras no Brasil e no Mundo (entre 1981 e 2003)

\begin{tabular}{|l|c|c|c|}
\hline \multicolumn{1}{|c|}{ Aspectos considerados } & \multirow{2}{*}{ Unidade } & \multicolumn{2}{c|}{ Abrangência } \\
\cline { 3 - 4 } & & Brasil & Mundo \\
\hline Área Degradada & $\left(\mathrm{km}^{2}\right)$ & 1.881 .702 & 35.058 .104 \\
\hline Área Degradada & $(\%$ do *território) & 22.11 & 23.54 \\
\hline Participação em Área Degradada global & $(\%)$ & 5,381 & - \\
\hline População afetada & (habitantes) & 46.595 .573 & 1.537 .679 .148 \\
\hline Ratio de População afetada & (\% do total) & 26.67 & 23.89 \\
\hline
\end{tabular}

${ }^{*} \mathrm{O}$ Território abrange a terra seca, excluídos os corpos hídricos continentais.

Fonte: Adaptado de Bai et al. (2008). 
Como resposta aos dilemas impostos pela sobre-exploração dos recursos naturais, o Estado brasileiro, por meio da Política Ambiental, vem disciplinando e criando mecanismos para a recuperação das áreas degradadas. Atualmente, o país dispõe de extenso conjunto normativo que determina a realização de Projetos de Recuperação de Áreas Degradadas (PRADs), como condicionantes das exigências impostas às atividades econômicas degradantes, por ocasião do licenciamento ou da compensação ambiental. À medida que essas exigências normativas se endurecem, demandando critérios mais objetivos que permitam atestar, de forma efetiva e iniludível, o status (situação) e a conclusão dos PRADs, cresce a demanda por ferramentas de monitoramento e avaliação desses projetos. Por exemplo, o Estado do Rio de Janeiro, através do Instituto Estadual do Ambiente (INEA), vem recentemente trabalhando em uma minuta de Resolução que pretende criar procedimentos de vistoria e monitoramento de projetos de recuperação mediante reflorestamentos heterogêneos. Por sua vez, o Estado de São Paulo, através da Secretaria do Estado do Meio Ambiente (SMA) e da Companhia Ambiental do Estado de São Paulo (CETESB), vem promovendo desde 2010, estudos sobre o monitoramento e a avaliação de projetos de reflorestamento e restauração ambiental. Essas pioneiras iniciativas estaduais demonstram a crescente demanda por parte dos órgãos ambientais brasileiros de adotar critérios mais eficazes e objetivos que lhes permitam melhor atestar a realização e a conclusão dos PRADs que fiscalizam. Tal conjuntura reafirma a crescente importância de estudos pragmáticos sobre o desenvolvimento de ferramentas de monitoramento e avaliação de PRADs.

Adicionalmente, o estudo das 'áreas degradadas' reúne contribuições oriundas de várias ciências, dado que o conceito envolve impactos sobre o solo como substrato físico, bem como sobre as esferas biológicas e hidrológicas, requerendo, portanto, dos PRADs, a realização de uma análise ecológica, sistêmica e multidisciplinar, o que por vezes representa um desafio não trivial e

complexo (ARAÚJO et al., 2010, DURIGAN \& ENGEL, 2012, TAVARES, 2008). Neste sentido, embora o conhecimento tenha avançado nas últimas décadas, aprimorando diversos aspectos do planejamento dos projetos, alguns 
desses processos ainda carecem de pesquisas e conceitos mais sólidos, especialmente no que concerne às etapas de monitoramento e avaliação dos PRADs.

Para melhor entendimento, o Monitoramento é um processo sistemático pelo qual periodicamente se checa, descreve e avalia o estado (status) de um PRAD, enquanto que a Avaliação consiste em uma série de ações destinadas a determinar se os objetivos propostos para a recuperação, ou restauração de uma área, foram ou estão sendo alcançados (HOWELL et al., 2012). Para melhor aproveitamento das informações derivadas das etapas de Monitoramento e Avaliação, faz-se necessário um Plano de Monitoramento, isto é, um planejamento prévio à implementação do projeto. Esse plano deverá refletir as metas e os objetivos do projeto de recuperação além de prever recursos, tarefas e prazos (ou períodos) de coleta das informações. Por sua vez, a avaliação das informações coletadas e dos resultados obtidos possibilitará subsidiar a tomada de decisão corretiva por parte do executor, além de reunir lições aprendidas como base para conhecimento do processo de restauração (BRANCALION et al., 2012).

Assim, resulta evidente que ambas as etapas constituem ferramentas gerenciais e estratégicas fundamentais, capazes de contribuir para o avanço do conhecimento sobre a recuperação, na medida que, em conjunto, permitem aprofundar a compreensão sobre os motivos do sucesso (ou falha) dos PRADs. Isto é, o monitoramento e a avaliação representam a melhor maneira de atestar a consecução dos objetivos e metas previamente definidos para um processo de restauração e, em maior escala, permitem definir a trajetória ambiental da área em recuperação bem como sua capacidade futura de sustentabilidade (HOWELL et al., 2012).

No entanto, a despeito da importância dessas etapas, verificam-se poucas pesquisas e literaturas disponíveis sobre o tema. Parte do problema reside no entendimento, por vezes simplório e equivocado, por parte de alguns órgãos licenciadores e empresas que executam serviços de restauração, que vêem essas etapas como sendo apenas o mero e formal cumprimento das exigências legais inerentes aos processos de licenciamento e compensação ambiental. Adicionalmente, em razão da polissemia de conceitos definidores do termo 'RAD', das diferentes técnicas de recuperação existentes, além das 
diferentes diretrizes normativas, comumente os PRADs apresentam objetivos de recuperação bem diferenciados. Nessa linha, verifica-se certo consenso na literatura acerca da inexistência de modelos (conceitos RAD + técnicas RAD) que possam ser homogeneamente aplicados no monitoramento e na avaliação de uma ampla gama de projetos, ecossistemas ou formações florestais (BELLOTTO et al., 2009; DOREN et al., 2009; EHRENFELD, 2009; RODRIGUES \& GANDOLFI, 2009; BRANCALION et al., 2012).

A seguir, serão descritas de forma sucinta, duas propostas de monitoramento e avaliação de PRADs. A primeira, de índole mais teórica, é considerada como referência no monitoramento e na avaliação de projetos de restauração ecológica, aqui designada como Proposta SER (2004). A segunda é uma proposta empírica derivada da primeira, com aplicabilidade na avaliação de PRADs do Bioma Mata Atlântica, que empreguem reflorestamentos heterogêneos com espécies nativas, denominada como Proposta de Melo et al. (2010).

\section{DIRETRIZES PARA O MONITORAMENTO E A AVALIAÇÃO EM PRADS: A PROPOSTA SER (2004)}

O processo de alteração intencional de um habitat denominado 'Restauração Ecológica' vem se consolidando como referência em projetos de recuperação de áreas degradadas, por apresentar um conjunto sólido de conhecimento teórico. Neste sentido, a Sociedade Internacional para a Restauração Ecológica - SER (Society for Ecological Restoration International) sugere diretrizes de restauração ecológica que vêm influenciando o trabalho de pesquisadores e restauradores em diversas partes do mundo, incluindo o Brasil (DURIGAN \& ENGEL, 2012).

A Proposta SER (2004) constitui um marco conceitual de referência que apresenta diretrizes universais para o monitoramento e a avaliação de PRADs, de forma a garantir o cumprimento das metas e objetivos individuais previamente traçados para os mesmos. A SER sugere a adoção de um protocolo universal de monitoramento e avaliação, ainda na fase de planejamento do projeto, que estabeleça objetivos e metas mensuráveis. Assim, o sucesso da recuperação, ou em última instância do próprio projeto, 
poderá ser mensurado pelo alcance dessas metas, que por sua vez, podem ser avaliadas em termos de padrões de desempenho, também conhecidos como 'critérios do projeto' ou 'critérios de êxito'.

Entretanto, a definição do sucesso de um projeto de restauração não é uma tarefa simples, uma vez que atestar o alcance dos objetivos e metas previamente estabelecidos dependerá em grande medida do desempenho de uma ampla gama de variáveis selecionadas para a produção dos indicadores ecológicos. Nesse sentido, a Proposta SER (2004) embora não pretenda especificar uma matriz própria de indicadores ecológicos, apresenta sua maior contribuição ao definir nove (9) atributos de ecossistemas restaurados, que devem ser, parcial ou integralmente apresentados, por uma área em recuperação, conforme descrição a seguir:

1) O ecossistema restaurado contém um conjunto característico de espécies que ocorrem no ecossistema de referência, fornecendo uma estrutura apropriada de comunidade;

2) O ecossistema restaurado consiste de espécies indígenas até o máximo grau possível. Nos ecossistemas culturais restaurados, permite-se a ocorrência de espécies exóticas domesticadas e de espécies ruderais não invasoras, além das arvenses, que presumidamente coevoluiram com elas. As espécies ruderais são representadas por plantas que colonizam sítios perturbados, enquanto as arvenses crescem entre plantas de cultivo;

3) Todos os grupos funcionais necessários para o desenvolvimento contínuo e/ou estabilidade do ecossistema restaurado encontram-se representados ou, caso não estejam presentes, os grupos ausentes possuem potencial para colonizar o ambiente por meios naturais;

4) O ambiente físico do ecossistema restaurado possui a capacidade de suportar as populações reprodutivas das espécies necessárias para sua estabilidade contínua ou desenvolvimento ao longo da trajetória desejada;

5) O ecossistema restaurado aparentemente funciona de modo normal, de acordo com seu estado ecológico de desenvolvimento, não existindo sinais de disfunção;

6) $\mathrm{O}$ ecossistema restaurado foi integrado adequadamente com a matriz 
ecológica ou a paisagem, com a qual interage através de fluxos e intercâmbios abióticos e bióticos;

7) As ameaças potenciais à saúde e à integridade do ecossistema restaurado foram eliminadas ou reduzidas ao máximo possível;

8) O ecossistema restaurado é suficientemente resiliente para suportar os eventos periódicos normais de estresse que ocorrem no ambiente local e que servem para manter a integridade do ecossistema;

9) O ecossistema restaurado é auto-sustentável, ao mesmo grau que seu ecossistema de referência, e possui o potencial para persistir indefinidamente sob as condições ambientais existentes.

Ademais, a Proposta SER (2004) apresenta três estratégias não excludentes para avaliar os projetos de restauração:

a) Análise de atributos. Nesta estratégia avaliam-se os nove atributos dos ecossistemas restaurados sugeridos pela SER, embora sem pretender descrever os indicadores deles derivados. Esta técnica reconhece ainda, que os dados quantitativos do monitoramento programado e de outros inventários são os mais viáveis para avaliar o alcance dos objetivos do projeto;

b) Comparação direta. Realiza-se a partir da medição dos parâmetros selecionados na área de referência e nos locais de restauração. É necessária uma descrição minuciosa dos parâmetros de comparação, que incluem aspectos bióticos e abióticos. Há ainda a questão de definir quantos parâmetros devem apresentar valores similares à área de referência para que sejam satisfeitos os objetivos da restauração e assim poder considerar o processo de recuperação como concluído;

c) Análise da trajetória. Trata-se de uma técnica ainda em fase de desenvolvimento voltada a interpretar grandes conjuntos comparativos. Nessa estratégia, os dados coletados periodicamente em áreas de recuperação, estabelecem tendências. Espera-se que as tendências traçadas possam conduzir às condições de referência desejadas, confirmando que a restauração segue a trajetória desejada. 
Assim, a partir da sistematização do conhecimento realizada pela Proposta SER (2004), tanto na definição dos atributos desejáveis aos ecossistemas restaurados, quanto no estabelecimento de estratégias de avaliação, essa proposta representa uma importante ferramenta de auxílio ao planejamento das etapas de monitoramento e avaliação de PRADs, que deveria ser observada por autores e/ou executores, que se dispusessem à contribuir na complexa tarefa de selecionar e desenhar indicadores $\boldsymbol{R A D}$.

\section{DIRETRIZES PARA O LEVANTAMENTO DE INDICADORES RAD: A PROPOSTA DE MELO ET AL. (2010)}

O Guia para Monitoramento de Reflorestamentos para Restauração elaborado por Melo et al. (2010) sugere uma Matriz de Avaliação de Projetos de Restauração com Reflorestamento Heterogêneo, que apresenta uma descrição detalhada de sete (7) indicadores RAD. A Proposta de Melo et al. (2010) tem sido utilizada como referência por órgãos ambientais brasileiros para o estabelecimento de parâmetros e procedimentos de monitoramento e avaliação de projetos de reflorestamentos heterogêneos com espécies nativas. Recentemente, a proposta foi adaptada pelo Instituto Estadual do Ambiente (INEA) do Estado do Rio de Janeiro, servindo como base para a elaboração de minuta de Resolução voltada a estabelecer parâmetros de fiscalização de PRADs a serem implementados em território fluminense.

A contribuição da Proposta de Melo et al. (2010) para guiar e auxiliar as etapas de monitoramento e avaliação através de indicadores RAD, enfatiza a análise da estrutura da comunidade em formação, bem como as medidas de controle da qualidade do reflorestamento, para assim garantir a qualidade do processo de recuperação durante os três primeiros anos do reflorestamento. Para o processo de levantamento dos indicadores RAD, os autores adotaram as seguintes diretrizes básicas:

a) Adoção de indicadores relevantes para restauração e sensíveis às alterações relacionadas ao manejo e à idade dos plantios;

b) Coleta de informações de campo facilmente compreendidas por qualquer técnico; 
c) Indicação de manejo relacionada a diferentes níveis de adequação de cada reflorestamento.

Assim, a partir dessas três diretrizes, os autores propuseram sete indicadores RAD, agrupados em três grupos, conforme as etapas da recomposição vegetal à que se relacionam:

a) Preparo. Envolvendo as tarefas de preparo da área para plantio, inclui os indicadores "Cercamento" e "Proteção de Perturbações";

b) Manutenção. Engloba as tarefas de manutenção do plantio sobre a área a ser recuperada. Inclui os indicadores "Mortalidade de mudas", "Ataque de formigas", "Matocompetição na coroa das mudas" e "Matocompetição na entrelinha";

c) Estrutura. Engloba o aspecto da estrutura da comunidade vegetal formada a partir do plantio. Inclui o indicador "Cobertura de copas (\%)".

Os indicadores RAD propostos apresentam-se organizados em uma Matriz de Avaliação de Projetos de Reflorestamento Heterogêneo, conforme a Tabela 2 a seguir. Como pretendido pelos autores, essa Matriz pode ser levada a campo e é facilmente compreensível por qualquer técnico encarregado de proceder à avaliação do reflorestamento. Para facilitar sua compreensão e entendimento, a Matriz encontra-se organizada por Grupo de Tarefas e Indicadores correspondentes, ademais de apresentar os seguintes aspectos de destaque:

a) Nível de Adequação. Atribui três (3) níveis de adequação para cada aspecto mensurado do indicador. Os níveis 2 e 3 pressupõem a necessidade de tomar medidas corretivas, que constam na coluna de 'Recomendações';

b) Valor Encontrado. Nesta coluna, o avaliador deve reportar o estado encontrado pelo aspecto mensurado pelo indicador, que pode ser quantitativo ou qualitativo (Ex: "área não cercada" ou "10\% de mortalidade");

c) Avaliação. Nesta coluna, o avaliador deve indicar o nível de adequação equivalente ao valor encontrado pelo aspecto mensurado pelo indicador, cabendo, portanto, valores que variem entre 1 a 3 ; 
d) Recomendação. Ações corretivas a serem tomadas no caso de verificação de desvios nos aspectos verificados pelos indicadores, ou seja, níveis de adequação 2 e 3 ;

e) Periodicidade. Informa a periodicidade de coleta das informações acerca dos indicadores mensurados.

Em razão da especificidade da Proposta de Melo et al. (2010), voltada exclusivamente para a recomposição vegetal, cabe destacar ainda algumas considerações adicionais:

a) Os indicadores propostos se limitam a monitorar e avaliar, direta ou indiretamente, o grau de desenvolvimento e a possibilidade de sucesso no plantio de mudas em projetos de restauração. Para tanto, os indicadores devem ser levantados em campo de acordo com o grau de desenvolvimento do plantio, tendo a periodicidade de medição especificada;

b) Os indicadores propostos não contemplam aspectos do monitoramento da estrutura física da área em recuperação, tais como a avaliação das condições do solo ou da hidrografia;

c) Os indicadores propostos foram desenvolvidos exclusivamente para auxiliar a avaliação de PRADS que empreguem a técnica de plantio em área total, não podendo assim ser recomendados para projetos que apliquem outras técnicas de restauração diferentes (como o adensamento, o enriquecimento, a nucleação, etc);

d) A aplicação desses indicadores é recomendada somente para formações florestais específicas da Mata Atlântica, compreendendo as Florestas Ombrófilas (Densa e Mista) e Estacionais (Semidecidual e Decidual), não podendo, portanto, ser replicada em outros biomas sem estudos ou adaptações específicas. 
Tabela 2. Matriz de Avaliação de Projeto de Reflorestamento Heterogêneo

\begin{tabular}{|c|c|c|c|c|c|c|c|c|}
\hline \multirow[t]{2}{*}{ Grupo } & \multirow[t]{2}{*}{ Indicador } & \multicolumn{3}{|c|}{ Nível de Adequação } & \multirow{2}{*}{$\begin{array}{c}\text { Valor } \\
\text { encontrado }\end{array}$} & \multirow[t]{2}{*}{ Avaliação } & \multirow[t]{2}{*}{ Recomendação } & \multirow[t]{2}{*}{ Periodicidade } \\
\hline & & 1 & 2 & 3 & & & & \\
\hline \multirow{2}{*}{$\begin{array}{l}\frac{0}{\pi} \\
\frac{0}{0} \\
\frac{1}{2}\end{array}$} & Cercamento & $\begin{array}{l}\text { Área completamente } \\
\text { cercada ou cercamento } \\
\text { desnecessário }\end{array}$ & $\begin{array}{l}\text { Área parcialmente } \\
\text { cercada }\end{array}$ & Área não cercada & & & Completar o isolamento nos pontos necessários & $\begin{array}{l}\text { Mensal no } 1^{\circ} \text { ano e } \\
\text { trimestral a partir do } 2^{\circ} \\
\text { ano }\end{array}$ \\
\hline & $\begin{array}{l}\text { Proteção de } \\
\text { perturbações }\end{array}$ & $\begin{array}{l}\text { Não se detectam sinais de } \\
\text { perturbação OU, quando } \\
\text { existem, não } \\
\text { comprometem mais que } \\
10 \% \text { da área }\end{array}$ & $\begin{array}{l}\text { São detectados sinais de } \\
\text { perturbação que } \\
\text { comprometem entre } 11 \text { e } \\
30 \% \text { da área }\end{array}$ & $\begin{array}{l}\text { São detectados sinais de } \\
\text { perturbação em mais de } \\
31 \% \text { da área }\end{array}$ & & & $\begin{array}{l}\text { Completar proteção para os elementos de } \\
\text { degradação detectados. Analisar o caso e definir } \\
\text { medidas para cessar perturbações em toda área }\end{array}$ & $\begin{array}{l}\text { Mensal no } 1^{\circ} \text { ano } \mathrm{e} \\
\text { trimestral a partir do } 2^{\circ} \\
\text { ano }\end{array}$ \\
\hline \multirow{4}{*}{ 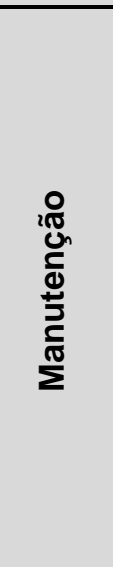 } & Mortalidade & $\begin{array}{l}\text { Até } 10 \% \text {, de forma } \\
\text { dispersa pelo plantio. }\end{array}$ & $\begin{array}{l}\text { Entre } 10 \text { e } 20 \% \text { OU } \\
\text { menor, localizada em } \\
\text { reboleiras }\end{array}$ & $\begin{array}{l}\text { Entre } 10 \text { e } 20 \% \text { em } \\
\text { clareiras OU acima de } \\
20 \% \text { dispersos na área }\end{array}$ & & & $\begin{array}{l}\text { Analisar causa da mortalidade e adotar medidas } \\
\text { necessárias de controle de doenças, pragas ou } \\
\text { adequação de espécies às condições ambientais }\end{array}$ & $\begin{array}{l}\text { Mensal no } 1^{\circ} \text { ano } \mathrm{e} \\
\text { trimestral a partir do } 2^{\circ} \\
\text { ano }\end{array}$ \\
\hline & $\begin{array}{l}\text { Ataque de } \\
\text { formigas }\end{array}$ & $\begin{array}{l}\text { Até } 15 \% \text { das árvores } \\
\text { parcialmente desfolhadas }\end{array}$ & $\begin{array}{l}\text { Entre } 16 \text { e } 30 \% \text { das } \\
\text { árvores parcialmente } \\
\text { desfolhadas OU até } 10 \% \\
\text { de árvores totalmente } \\
\text { desfolhadas } \\
\end{array}$ & $\begin{array}{l}\text { Mais de } 30 \% \text { de árvores } \\
\text { parcialmente desfolhadas } \\
\text { OU mais de } 10 \% \text { das } \\
\text { árvores totalmente } \\
\text { desfolhadas }\end{array}$ & & & $\begin{array}{l}\text { Analisar espécie infestante, condições climáticas } \\
\text { e adotar técnica de controle. Analisar se houve } \\
\text { mortalidade e, caso necessário, realizar replantio }\end{array}$ & $\begin{array}{l}\text { Mensal no } 1^{\circ} \text { ano } \mathrm{e} \\
\text { trimestral a partir do } 2^{\circ} \\
\text { ano }\end{array}$ \\
\hline & $\begin{array}{l}\text { Matocompetição } \\
\text { na coroa das } \\
\text { mudas }\end{array}$ & $\begin{array}{l}\text { Ocorrência de } \\
\text { competidoras em até } 25 \% \\
\text { da coroa }\end{array}$ & $\begin{array}{l}\text { Observa-se ocorrência de } \\
\text { competidoras em área } \\
\text { entre } 26 \text { e } 50 \% \text { das } \\
\text { coroas }\end{array}$ & $\begin{array}{l}\text { Observa-se ocorrência de } \\
\text { competidoras em área } \\
\text { maior que } 50 \% \text { da área } \\
\text { das coroas }\end{array}$ & & & $\begin{array}{l}\text { Analisar espécie infestante, condições climáticas } \\
\text { e priorizar região da coroa das mudas para } \\
\text { adoção de medidas manuais, químicas ou } \\
\text { mecânica de controle de infestantes das mudas }\end{array}$ & $\begin{array}{l}\text { Mensal no } 1^{\circ} \text { ano e } \\
\text { trimestral a partir do } 2^{\circ} \\
\text { ano }\end{array}$ \\
\hline & $\begin{array}{l}\text { Matocpmpetição } \\
\text { na entrelinha }\end{array}$ & Menor que $30 \%$ da área & $\begin{array}{l}\text { Observa-se ocorrência de } \\
\text { competidoras em área } \\
\text { equivalente a } 30-50 \% \\
\text { da área }\end{array}$ & $\begin{array}{l}\text { Mais de } 50 \% \text { da } \\
\text { matocompetição dispersa } \\
\text { nas entrelinhas }\end{array}$ & & & $\begin{array}{l}\text { Analisar espécie infestante, condições climáticas } \\
\text { e adotar medidas manuais, químicas ou } \\
\text { mecanizadas de controle de infestantes das } \\
\text { mudas }\end{array}$ & $\begin{array}{l}\text { Mensal no } 1^{\circ} \text { ano } \mathrm{e} \\
\text { trimestral a partir do } 2^{\circ} \\
\text { ano }\end{array}$ \\
\hline$\frac{\substack{0 \\
\frac{2}{3}}}{3}$ & $\begin{array}{l}\text { Cobertura de } \\
\text { copas }\end{array}$ & $\begin{array}{l}\text { Acima de } 80 \% \text { do valor na } \\
\text { melhor área de mesma } \\
\text { idade na mesma } \\
\text { microbacia }\end{array}$ & $\begin{array}{l}\text { Entre } 50 \text { e } 80 \% \text { do valor } \\
\text { na melhor área de mesma } \\
\text { idade na mesma } \\
\text { microbacia }\end{array}$ & $\begin{array}{l}\text { Abaixo de } 50 \% \text { do valor } \\
\text { na melhor área de mesma } \\
\text { idade na mesma } \\
\text { microbacia. }\end{array}$ & & & $\begin{array}{l}\text { Verificar se o conjunto de espécies plantadas } \\
\text { contempla aquelas de maior crescimento na } \\
\text { região e proceder ao adensamento associado } \\
\text { com outras medidas de adequação dos } \\
\text { indicadores do grupo Manutenção }\end{array}$ & $\begin{array}{l}\text { Trimestral no } 1^{\circ} \text { ano } \mathrm{e} \\
\text { semestral a partir do } 2^{\circ} \\
\text { ano }\end{array}$ \\
\hline
\end{tabular}

Fonte: Adaptado de Melo et al. (2010). 


\section{CONCLUSÕES}

A aplicabilidade de uma proposta de Monitoramento e Avaliação de um Projeto de Recuperação de Área Degradada (PRAD) dependerá, em grande medida, da solidez dos conceitos que orientem esse projeto. Nesse sentido, a Sociedade Científica SER (Society for Ecological Restoration International) desenvolveu, a partir da contribuição de vários pesquisadores que a integram, a denominada Proposta SER (2004). Trata-se de um documento que identifica nove (9) atributos desejáveis que devem ser, parcial ou integralmente apresentados, por uma área em restauração. Assim, ainda que de forma indireta, a Proposta SER (2004) apresenta diretrizes universais para a produção de indicadores de restauração ecológica.

Por sua vez, os sete (7) indicadores RAD da Proposta de Melo et al. (2010) guardam similaridade e coerência conceitual com a Proposta SER (2004). A proposta dos autores constitui uma aplicação prática, em âmbito nacional, das sugestões da sociedade científica para o levantamento de indicadores RAD. De forma empírica, a Proposta de Melo et al. (2010) vem sendo adotada por órgãos ambientais dos Estados do Rio de Janeiro e São Paulo. Por outro lado, a especificidade dessa proposta para o bioma Mata Atlântica, não se torna propriamente um problema, uma vez que permite que 0 monitoramento ganhe em termos de riqueza de detalhes, favorecendo outros estudos correlatos no mesmo bioma, embora possa, logicamente, perder em termos de replicabilidade em outras fitofisionomias ou ecossistemas.

Finalmente, transcendendo ambas as propostas analisadas, sem subestimar suas valiosas contribuições para o avanço do monitoramento e da avaliação de áreas em recuperação, cabe destacar que restam ainda algumas lacunas nesse conhecimento. A primeira delas diz respeito à dificuldade temporal e financeira da amostragem de grande áreas em recuperação. Por exemplo: Melo et al. (2010) sugerem, para áreas acima de 3 ha, coletar uma amostra a cada 0,1 ha. Ou seja, para uma área em recuperação de 50 ha, dever-se-ia coletar um total de 500 amostras. Tal magnitude inviabilizaria a operacionalidade do projeto, especialmente considerando a realidade dos órgãos ambientais estaduais, que por vezes devem fiscalizar áreas cuja dimensão global ultrapassa os milhares de hectares.

Uma segunda questão objeto de estudo é a determinação do momento 
exato em que uma área em recuperação atinge um patamar de autossustentabilidade em seus processos de renovação ecológica, pelo que não mais necessita da intervenção humana. Uma vez que os PRADs têm sua origem em processos de compensação ambiental, fruto de condicionantes de licenciamento ou infração ambiental, o ordenamento jurídico demanda uma posição técnica que permita concluir a obrigação imposta à compensação arbitrada. Ou seja, identificar o momento ecológico de conclusão de um PRAD representa outro importante desafio de pesquisa na área.

\section{REFERÊNCIAS}

ADEEL, Z., SAFRIEL, U., NIEMEIJER, D., WHITE, R., Ecosystems and Human Well-being: Desertification Synthesis. A Report of the Millennium Ecosystem Assessment. Washington: World Resources Institute, 2005. 36p.

ARAÚJO, G. H. S., ALMEIDA, J. R., GUERRA, A. J. T. Gestão ambiental de áreas degradadas. 6ª $\mathrm{Ed}$. Rio de Janeiro: Bertrand Brasil, 2010. 322p.

BAI, Z.G.; DENT, D.L.; OLSSON, L.; SCHAEPMAN, M.E. Global assessment of land degradation and improvement: Identification by remote sensing. Wageningen: ISRIC, 2008. 69 p. (Report 2008/1).

BELLOTTO, A.; VIANI, R.A.G.; NAVE, A.G.; GANDOLFI, S.; RODRIGUES, R.R. Monitoramento das Áreas Restauradas como Ferramenta para Avaliação da Efetividade das Ações de Restauração e para Redefinição Metodológica. In: RODRIGUES, R.R.; BRANCALION, P.H.S.; ISERNHAGEN, I. Pacto pela Restauração da Mata Atlântica: Referencial dos Conceitos e Ações de Restauração Florestal. São Paulo: LERF/ESALQ: Instituto Bioatlântica, 2009. Cap. 3, p. $128-146$.

BRANCALION, P. H. S.; VIANI, R. A. G. ; RODRIGUES, R. R. ; GANDOLFI, S. Avaliação e Monitoramento de Áreas em Processo de Restauração. In: MARTINS, S.V. (Org.). Restauração Ecológica de Ecossistemas Degradados. Viçosa: Editora UFV, 2012, Cap. 9, p. 262-293.

DOREN, R.F., TREXLER, J.C., GOTTLIEB, A.D., HARWELL, M. C. Ecological indicators for system-wide assessment of the greater everglades ecosystem restoration program. Ecological Indicators, V. 9, I 6, Suplemento, p. S2-S16, Nov./ 2009. 
DURIGAN, G.; ENGEL, V.L. Restauração de Ecossistemas no Brasil: Onde estamos e para onde podemos ir? In: MARTINS, S.V. Restauração Ecológica de Ecossistemas Degradados. Viçosa: UFV, 2012. Cap. 2, p. 41-68.

EHRENFELD, J.G., Defining the Limits of Restoration: The Need for Realistic Goals. Restoration Ecology, V.8, № 1, p. 2 - 9, mar / 2009.

HOWELL, E.A., HARRINGTON, J.A., GLASS, S.B. Introduction to Restoration Ecology. Washington: Island Press, 2012. 418p..

MELO, A.C.G.; REIS, C.M.; RESENDE, R.U. Guia para Monitoramento de Reflorestamentos para Restauração. Circular Técnica 1 Projetos Mata Ciliar, São Paulo: Secretaria de Meio Ambiente, n. 1, 2010. 10 p.

RODRIGUES, R.R.; GANDOLFI, S. Conceitos, tendências e ações para a recuperação de florestas ciliares. In. Rodrigues R. R. \& Leitão Filho H. de F. (eds) Matas ciliares: conservação e recuperação. São Paulo: EDUSP, 2009. Cap. 15.1, p. 235-247.

RODRIGUES, R.R.; GANDOLFI, S. Conceitos, tendências e ações para a recuperação de florestas ciliares. In. Rodrigues R. R. \& Leitão Filho H. de F. (eds) Matas ciliares: conservação e recuperação. São Paulo: EDUSP, 2009. Cap. 15.1, p. 235-247.

SER - SOCIETY FOR ECOLOGICAL RESTORATION INTERNATIONAL, Grupo de Trabalho sobre Ciência e Política. Princípios da SER Internacional sobre Restauração Ecológica. Tradução de Griffith, J.J. et al. Tucson, 2004. $15 p$.

TAVARES, S.R.L. et al. Curso de recuperação de áreas degradadas: a visão da Ciência do Solo no contexto do diagnóstico, manejo, indicadores de monitoramento e estratégias de recuperação. Série Documentos / Embrapa Solos, 103. Rio de Janeiro: Embrapa Solos, 228 p. 2008.

VOGT, J. V., SAFRIEL, U., Von MALTITZ, G., SOKONA, Y., ZOUGMORE, R., BASTIN, G. and HILL, J., Monitoring and assessment of land degradation and desertification: Towards new conceptual and integrated approaches. Land Degradation \& Development, V. 22. p. 150-165, 2011

Recebido: 01/10/2014

Aprovado: 29/11/2014 